\title{
Tiller Length vs. Tiller Weight: Applications to Plant Growth Studies
}

\author{
STEVEN H. SHARROW
}

\begin{abstract}
The growth and development of individual grass tillers is frequently monitored in intensive studies of plant response to treatments or environmental parameters. Since growth may be recognized as an increase in tiller weight or tiller length over time, knowledge of the relationship between them is important if researchers are to select the measure most appropriate for their needs. To make these comparisons, the mean weight and length of tillers from perennial ryegrass (Lolium perenne L.), colonial bentgrass (Agrostis tenuis Sibth.), softchess (Bromus mollis L.), and annual fescue (Vulpia Spp.) were measured on each of seven dates during the spring growing period, 1977 . Sample sizes required to estimate mean tiller length were calculated on each date using Stein's two-stage procedure. The relationship between mean tiller weight and mean tiller length over time was evaluated by least squares analysis of a linear regression model. Results of these analyses indicated that mean tiller length can be estimated satisfactorily from a substantially smaller sample size than can mean tiller weight. In addition, a strong linear relationship was observed between mean tiller weight and mean tiller length over time. The strength and linear nature of this relationship suggests that both measures will yield similar relative growth curves when sequential observations are plotted over time. Actual growth curves plotted for perennial ryegrass and colonial bentgrass support this supposition. Therefore, since tiller lengths require a small sample size to estimate each mean, both time and money can be saved by basing growth analysis on observations of tiller length rather than on tiller weight.
\end{abstract}

Plant growth is often monitored to assess the effects of treatments on plant productivity and development in range and pasture studies. In studies of inter-specific plant competition and plantherbivore interactions, the distribution of plant growth during the growing season may be as important as the total amount of aerial biomass accumulated over the entire season. The study reported here grew out of a need to determine the relative growth curves of different grass species growing together in a mixed sward. High variability in plant distribution and plant size within the sward, the relatively small area available for study, and the need to measure growth for each species separately made the use of plot-based or plant-based techniques impractical. The intensive nature of the study suggested the use of a tiller-based technique.

In intensive growth analyses, individual grass tillers of ten serve as the unit of observation for determining plant growth. Plant growth is generally measured quantitatively as an increase in weight or height over time. For example, Nelson et al. (1978) described growth rates in several populations of tall fescue (Festuc arundinacea, Schreb.) in $\mathrm{mg} /$ day and Beaty et al. (1978) reported

Author is assistant professor, Rangeland Resources Program, Oregon State University, Corvallis 97331 .

This article is submitted as Technical Paper No. 4999. Oregon Agricultural Experiment Station, Corvallis, Oregon 97331

Manuscript received January 7, 1980. tiller weights in their study of tall fescue development while McCarty (1938), McCarty and Price (1942), and Joy et al. (1954) defined plant growth as an increase in height of individual plants. Since growth may be expressed in either units of weight or height, it is important to know the relative efficiency of using each unit and the relationship between them. The purpose of this paper is to evaluate (1) the relative efficiency of using tiller weight vs. tiller length as a measure of growth in perennial ryegrass and colonial bentgrass and (2) the strength of relationship between mean tiller length and mean tiller weight over time for perennial ryegrass (Lolium perenne L.), colonial bentgrass (Agrostis tenuis Sibth.), annual fescues (Vulpia spp.), and softchess (Bromus mollis L.).

\section{Materials and Methods}

This study was conducted on two contiguous plots, one fertilized with $34 \mathrm{~kg} /$ ha of ammonium nitrate on May 1, 1977, and the other an unfertilized control plot. The study area was located approximately $1 \mathrm{~km}$ west of Corvallis, Oregon. Elevation is approximately $100 \mathrm{~m}$. Annual precipitation is approximately $100 \mathrm{~cm}$. Both plots supported a mixed stand of vegetation containing approximately $40 \%$ subterranean clover (Trifolium subterraneum L.), $26 \%$ perennial ryegrass, $18 \%$ colonial bentgrass, $5 \%$ annual grasses, and $11 \%$ broadleaf forbs by cover on March 30, 1977. These two plots were repeatedly sampled on seven dates during the spring growing season (between May 5 and June 10) in 1977. Care was taken to disturb the plots as little as possible during sampling. Traffic on the plots was not observed to be a problem. For each sampling date, the first 25 tillers each of perennial ryegrass and colonial bentgrass together with the first 25 tillers of annual grass encountered by the pins of randomly placed ten-point frame (Sharrow and Tober 1979) were sampled. This sampling regime was designed to select both vegetative and reproductive tillers in proportion to their density in the population. In the initial sampling (May 5), all tillers were vegetativc. As plant phenology progressed through the growing season, the ratio of vegetative/reproductive tillers in the sample decreased. Virtually all reproductive tillers were encountered on May 5, May 5, May 27, and June 10 for annual fescues, perennials ryegrass, softchess, and colonial bentgrass, rcspcctively. Sample tillers were clipped off at the soil surface, then taken to the laboratory where they were oven-dried at $50^{\circ} \mathrm{C}$ for 72 hours. Tiller length was then determined to the nearest millimeter by straightening the tiller along a meter stick. Length was measured from the base of the culm to the tip of the longest leaf. Oven-dry tillers were subsequently weighted to the nearest hundredth of a milligram on an analytical balance.

The least squares relationships between mean tiller length $(X)$ and mean tiller weight $(\mathrm{Y})$ were determined using a simple linear regression procedure (Steel and Torrie 1960). The resulting regression equations of fertilized vs. unfertilized plots were compared for homogeneity of regression coefficients. No differences were evi- 
dent. Therefore, data from fertilized and unfertilized plots were pooled for all further analysis.

\section{Results and Discussion}

The high $r^{2}$ values observed for all grass species examined in this study indicate that the linear relationship between mean tiller lenght and tiller weight over time was strong (Table 1). Mean tiller length is a powerful predictor accounting for 65 to $94 \%$ of the observed variability in mean tiller wcight. Standard errors of the estimate were moderately low, ranging from 9 to $28 \%$ of mean tiller weight. The lowest $r^{2}(0.65)$ and highest $S y . x$ expressed as a percentage of the mean $(28 \%)$ occurred in the annual fescue group.

Table 1. Least squares estimates for simple linear regression between mean tiller length $(\mathrm{mm})=\mathrm{X}$ and mean tiller weight $(\mathrm{mg})=\mathrm{Y}$ of four grass species based upon $n$ observations.

\begin{tabular}{llrcc}
\hline \multicolumn{1}{c}{ Plant species } & Regression line & $\mathrm{n}$ & $r^{2}$ & Sy.x $(\mathrm{mg})$ \\
\hline Perennial ryegrass & $\mathrm{Y}=0.60 \mathrm{X}-40.6$ & 14 & $0.94^{*}$ & 30.0 \\
Colonial bentgrass & $\mathrm{Y}=0.31 \mathrm{X}-6.9$ & 14 & 0.94 & 8.3 \\
Annual fescue & $\mathrm{Y}=0.13 \mathrm{X}-8.8$ & 9 & $0.65^{*}$ & 10.2 \\
Softchess & $\mathrm{Y}=0.24 \mathrm{X}-20.3$ & 10 & $0.94^{*}$ & 5.7 \\
\hline
\end{tabular}

'Significant at $P<0.01$.

Annual grasses can be difficult to identify in the vegetative stage even with the assistance of a vegetative key. While identification was not a problem with a distinctive species, such as softchess, it was a problem with relatively nondescript species such as the annual fescues. Even though all of the plants included in this group had similar tiller morphology, the inclusion of several species into a group, either intentionally or through misidentification, substantially weakened the length/weight relationship. It thus appears the grouping of species for the purpose of estimating a common mean tiller length/weight relationship should be avoided even if the plants have similar morphologies.

The strong linear relationship between mean tiller length and mean tiller weight indicates that these two units of measure will yield similar growth accumulation curves for the grasses studied with the possible exception of the annual fescues (Figs. 1 and 2). The growth accumulation curves based upon mean tiller weight and mean tiller length plotted in Figures 1 and 2, when compared for homogeneity of regression coefficients, revealed no meaningful differences $(P>.10)$. Therefore, proportional rates of growth calculated from either length increase or weight increase over time should be similar when expressed as a percentage of total growth observed. This concept is further substantiated by Scott's (1961) work in which increase in leaf length and biomass gave similar proportional growth rates for three perennial tussock grasses.

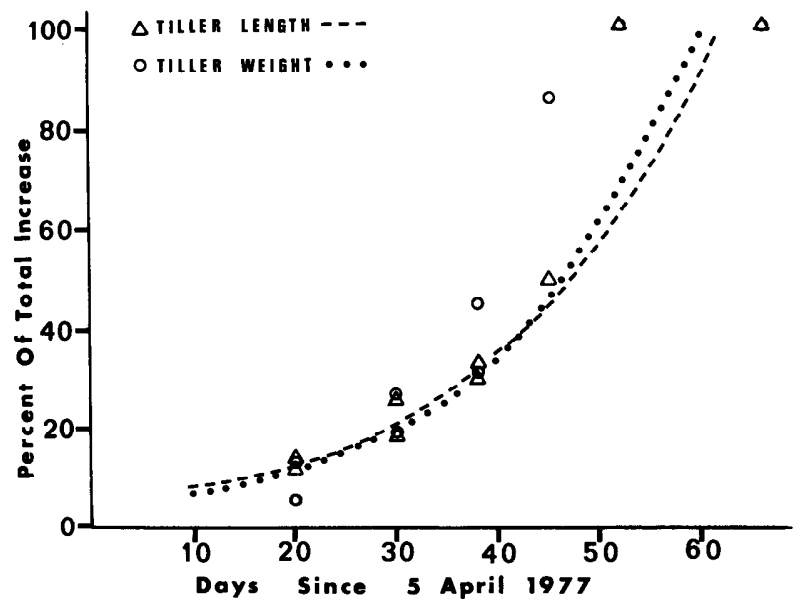

Fig. 1. Relative growth curves of perennial ryegrass tillers based upon mean tiller length and mean tiller weight.
Table 2. Coefficient of variation (C.V.) and minimum sample size (n) required to estimate mean perennial ryegrass tiller length and tiller weight on seven dates.

\begin{tabular}{lccccc}
\hline \hline & \multicolumn{2}{c}{ C.V. (\%) } & & \multicolumn{2}{c}{$n^{\prime}$} \\
\cline { 2 - 3 } \cline { 6 - 6 } Date & Length & Weight & & Length & Weight \\
\hline $05 / 05 / 77$ & 27 & 46 & & 29 & 85 \\
$26 / 04 / 77$ & 32 & 95 & & 41 & 364 \\
$05 / 05 / 77$ & 36 & 107 & & 52 & 462 \\
$13 / 05 / 77$ & 26 & 63 & & 27 & 159 \\
$20 / 05 / 77$ & 21 & 56 & & 17 & 124 \\
$27 / 05 / 77$ & 16 & 46 & & 11 & 84 \\
$10 / 06 / 77$ & 24 & 51 & & 22 & 106 \\
\hline
\end{tabular}

'Sample size required to estimate the mean $\pm 10 \%$ with $95 \%$ confidence. (Stein 1945 )

Although similar estimates of proportional growth rate may be obtained from either tiller length or tiller weight, the efficiency of obtaining these estimates varies substantially for the two measures. The coefficient of variation was generally two to three times as great for samples of tiller weight as it was for samples of tiller length in both perennial ryegrass (Table 2) and colonial bentgrass (Table 3). As a result of the higher variation observed in tiller weights, more tillers must be examined to estimate mean tiller weight than are required to estimate mean tiller length at a given level of accuracy and confidence. For example, on April 5 a sample containing 85 ryegrass tillers was required to estimate mean tiller weight within $10 \%$ of the true mean with $95 \%$ confidence. Only 29 tillers are required to secure an equivalent estimate of tiller length. Observations indicate that the amount of time required to locate and measure an individual tiller was approximately the same regardless of whether length or weight was measured. Therefore, the smaller sample size required to estimate mean tiller length

Table 3. Coefficient of variation (C.V.) and minimum sample size (n) required to estimate mean colonial bentgrass tiller length and tiller weight on seven dates.

\begin{tabular}{lccccc}
\hline \hline & \multicolumn{2}{c}{ C.V. $(\%)$} & & \multicolumn{2}{c}{$\mathrm{n}^{\prime}$} \\
\cline { 2 - 3 } \cline { 6 - 6 } Date & Length & Weight & & Length & Weight \\
\hline $05 / 04 / 77$ & 20 & 46 & & 16 & 83 \\
$26 / 04 / 77$ & 23 & 91 & & 21 & 331 \\
$05 / 05 / 77$ & 29 & 75 & & 34 & 225 \\
$13 / 05 / 77$ & 36 & 66 & & 52 & 164 \\
$20 / 05 / 77$ & 18 & 60 & & 13 & 144 \\
$27 / 05 / 77$ & 19 & 59 & & 14 & 139 \\
$10 / 06 / 77$ & 26 & 52 & & 27 & 108 \\
\hline
\end{tabular}

'Sample size required to estimate the mean $\pm 10 \%$ with $95 \%$ confidence. (Stein 1945).

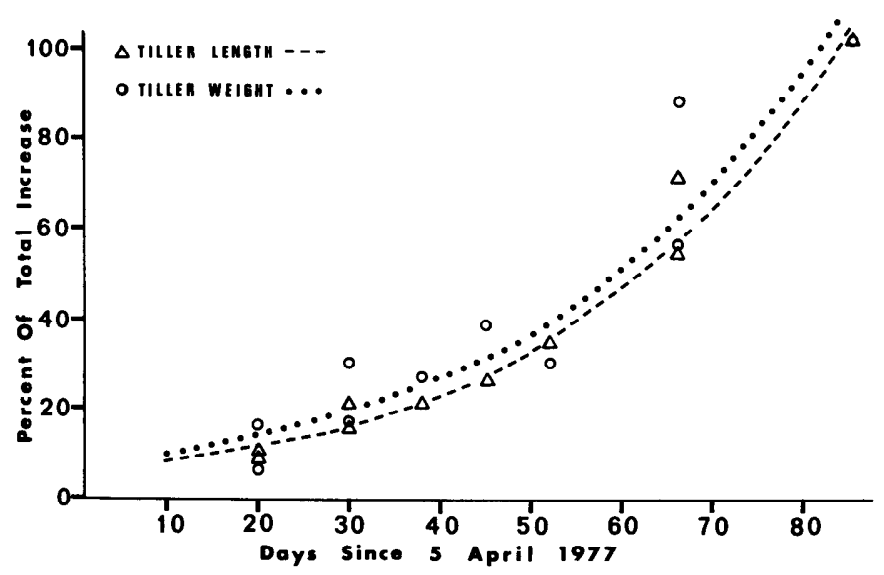

Fig. 2. Relative growth curves of colonial bentgrass tillers based upon mean tiller length and mean tiller weight. 
compared to mean tiller weight represented a true increase in efficiency directly proportional to the ratio of the sample sizes required. this increase in efficiency ranged from approximately 300 to $900 \%$ and 300 to $1600 \%$ for perennial ryegrass and colonial bentgrass, respectively. Thus, growth analyses based upon observations of tiller lengths may be done in one third or less of the time requires to perform a similar analysis based upon tiller weights.

The harvest of tillers which is required to measure tiller wcight is a further disadvantage of that technique. Tiller removal not only reduces the population of tillers available for future study but may also effect plant growth by reducing the plant's photosynthetic area. Therefore, tiller length, a non-destructive measure, may be preferable to tiller weight where objectives of the experiment or small plot size require that individual plants be sampled several times during the growing season.

\section{Conclusions}

A strong linear relationship was observed between length and weight of tillers from three of the four species examined. The relatively high $r^{2}$ and low $S y . x$ values obtained for these three species indicate that tiller length is a sensitive predictor of mean tiller weight. More importantly, however, the strength and linear nature of this relationship suggests that plant growth curves derived from either mean tiller length or mean tiller weights mea- surements will be similar. Since tiller lengths require a smaller sample size to estimate the mean, both time and money can be saved by basing growth analysis on observations of tiller length rather than tiller weight.

\section{Literature Cited}

Beaty, E.R., J.W. Dobson, and A.E. Smith. 1978. Tall fescue tiller weights, green forage present, and forage IVDMD. Agron. J. 70:223-226.

Joy, C.R., L. Helwig, T. Reiger, and M. Supola. 1954. A comparison of grass growth on different horizons of three grassland soils. J. Range Manage. 7:212-214.

McCarty, E.C. 1938. The relation of growth to varying carbohydrate content in mountain brome. U.S. Dep. Agr. Tech. Bull. 598. 24 p.

McCarty, E.C., and K. Price. 1942. Growth and carbohydrate content of important mountain forage plants in central Utah as affected by clipping and grazing. U.S. Dep. Agr. Tech. Bull. 818. 51 p.

Nelson, C.J., K.J. Treharne, and J.P. Cooper. 1978. The influence of tcmperature on leaf growth of diverse population of tall fescue. Crop Sci. 18:217-220.

Scott, D. 1961. Methods of measuring growth in short tussocks. New Zealand J. Agron. Res. 4:282-285.

Sharrow, S.H., and D.A. Tober. 1979. A simple, light weight point frame. J. Range Manage. 32:75-76.

Steel, R.G.D., and J.H. Torrie. 1960. Principles and Procedures of Statistics. McGraw-Hill Book Co., New York. 481 p.

Stein, C. 1945. A two-sample test for linear hypothesis whose power is independent of the variance. Ann. Math. Stat. 16:243-258.

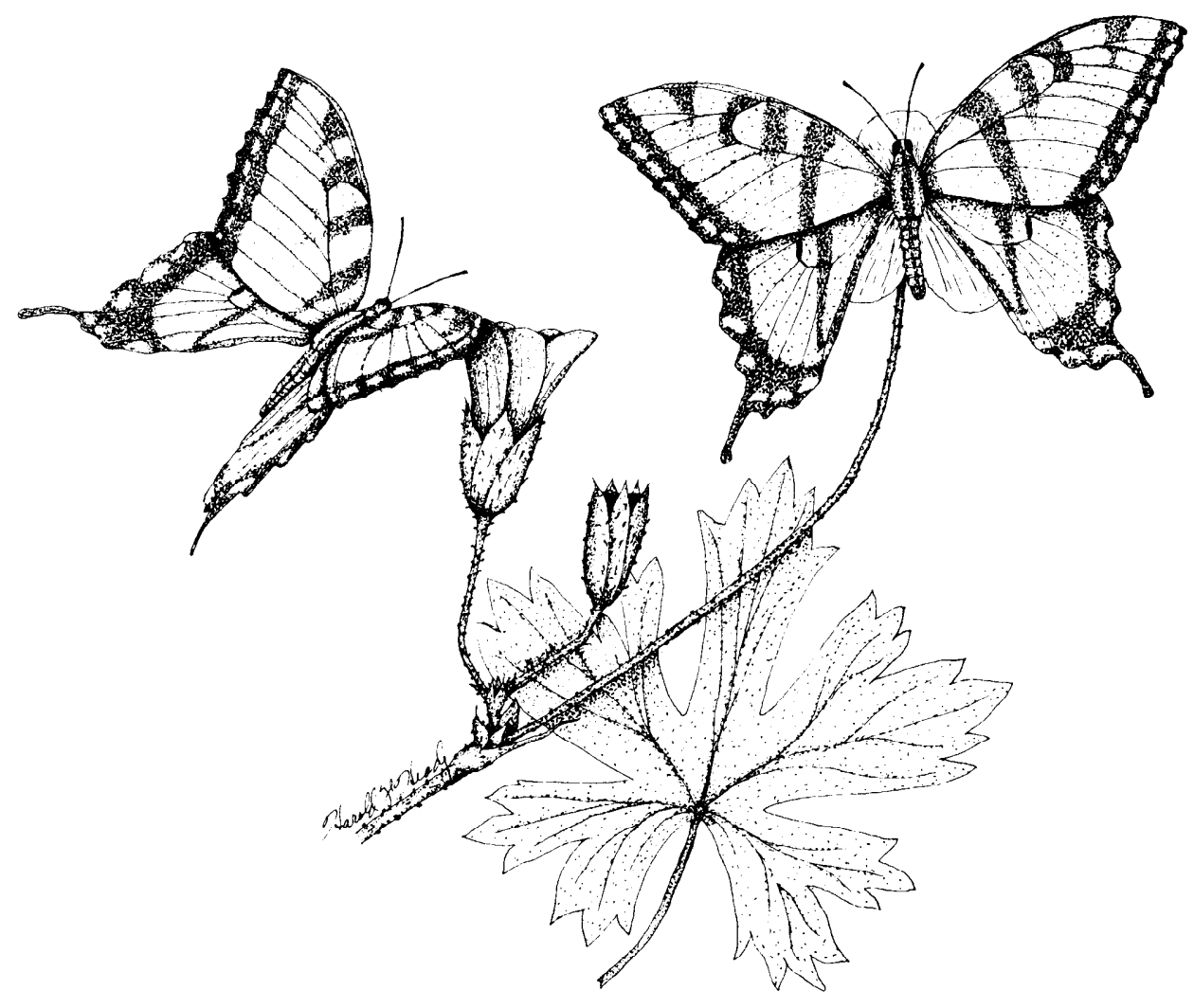

